\title{
Management of Widespread Pain and Fibromyalgia
}

Daniel Whibley, BA (Hons), MA, BSC (Hons)

Linda E. Dean, PhD, BSC (Hons), HND

Neil Basu, MD, PhD*

\author{
Address \\ *Epidemiology Group, Institute of Applied Health Sciences, University of \\ Aberdeen, School of Medicine and Dentistry, Foresterhill, Aberdeen, Scotland, \\ AB25 2ZD, UK \\ Email: neilbasu@abdn.ac.uk
}

Published online: 13 0ctober 2016

(C) The Author(s) 2016. This article is published with open access at Springerlink.com

This article is part of the Topical Collection on Pain

Keywords Fibromyalgia $\cdot$ Chronic widespread pain

\section{Opinion statement}

Specialists' views of fibromyalgia (FM) are typically colored by their experiences of the selected, complex cases that they are regularly called to evaluate. At a population level, it is crucial to recognize that education which promotes patient empowerment and non-pharmacological interventions which support self-management are very effective. The temptation, for both physician and patient, to first reach for pharmacological interventions should be resisted until such holistic approaches are explored. In particular, a strong evidence base supports graded exercise and cognitive behavioral therapies, but such treatments must be intelligently "prescribed." As reflected by the recent ACR criteria, FM is a highly heterogeneous disorder and is not simply a disorder of pain. For some patients, co-occurring symptoms, such as fatigue, can be equally as impactful and so management strategies should be sufficiently versatile to target those dimensions which are considered priorities at the level of the individual patient. In those patients who do require pharmacological support, patients should not be led to expect significant gains in isolation. The importance of self-management requires emphasis at each and every tier of management. It is true that advances in our understanding of neurobiology have greatly informed the selection of adjunctive drug classes which may provide benefit (as well as those which do not-as is the case of opioids). However, further unpicking of pathogenesis is still required if the FM landscape is to move further towards drug-led management.

\section{Introduction}

Proposed genealogies of the syndrome now known as fibromyalgia (FM) stretch back as far as the late sixteenth century [1]. Key historical moments in its emergence as a distinct entity include the 1904 debut 
of fibrositis [2] and Hench's introduction of the term "fibromyalgia" in 1976 [3]. The American College of Rheumatology (ACR) first published classification

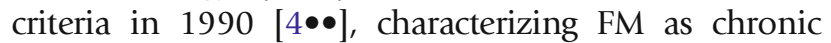
widespread pain (pain in the axial skeleton and on both sides of the body, above and below the waist, for at least 3 months), plus 11 out of a possible 18 tender points on clinical examination. The ACR disseminated revised criteria in 2010, the update shifting the emphasis from classification to diagnosis $[5 \bullet \bullet]$. The tender point requirement was replaced by recognition of the importance of patient-reported symptoms, including somatic, cognitive, and mood disorders. The revised criteria allowed FM to be measured on a continuous scale that incorporated the widespread-ness of pain and the severity of concurrent symptoms. A modified version of the 2010 criteria was published a year later (2011), and these were used to develop a questionnaire for use in clinical and epidemiological studies of the syndrome
$[6 \bullet \bullet]$. The mean worldwide prevalence of FM has been estimated to be $2.7 \%$, with a higher occurrence in women and those of middle or older age and lower socioeconomic status [7]. US prevalence has been estimated as $2.2 \%$ using the 1990 ACR criteria [8] and $6.4 \%$ using the 2010 ACR criteria [9]. Advances in the understanding of the underlying pathophysiology, including recognition of the role of central pain sensitization, have informed FM management. Findings from studies investigating pharmacological, non-pharmacological and complementary, and alternative therapies have been summarized in clinical practice guidelines (CPG). These include The European League Against Rheumatism's (EULAR) appraisal of the literature, published in 2008 [10•], which is currently being updated. This document was one of six CPGs that contributed to a systematic review of guidelines published up to 2014 [11••] which forms the basis of the evidence provided below.

\section{Treatment}

Given the heterogeneous symptomology of FM, it may be unsurprising that multimodal, multidisciplinary management has been widely advocated. This approach was supported by the highest level of evidence grading (A1: several randomized clinical trials with $p<0.01$ with metaanalysis) and the strongest possible recommendation (A: benefit significantly outweighs adverse effects and should be applied to all eligible patients) in a recent systematic review of CPGs $[11 \bullet \bullet]$ that included German and Canadian recommendations $[12 \bullet, 13 \bullet]$. Emphasis is placed on patient education and self-management, with the integration of nonpharmacological and then pharmacological treatments as indicated by concomitant, uncontrolled symptoms, including severe pain, mood disorders, sleep problems, and fatigue. Two non-pharmacological treatments have received the highest ratings for level of evidence: exercise and cognitive behavioral therapy (CBT) $[11 \bullet \bullet]$. Accordingly, nonpharmacological treatment options are considered first here, followed by pharmacological treatments, and then complementary and alternative therapies. The development and effectiveness of management plans that select from this pool of options would sensibly be stratified according to the individual patient's priorities. The revised Fibromyalgia Impact Questionnaire (FIQR) is one useful tool which may aid the multidisciplinary team in the design of bespoke multimodal therapy packages. This reliable and valid multidimensional assessment can also be employed to monitor function, symptoms, and the overall impact of FM over time [14]. 
Non-pharmacological treatment

\section{Education}

Patient education is the keystone of multimodal FM management. The educational component should develop the individual's understanding of the pathophysiology of FM, especially the recent advances in neurobiology, in the context of a biopsychosocial model of health and illness. Education regarding the importance of self-management that includes information on exercise, sleep habits, and the setting of realistic expectations, should be supported $[13 \bullet, 15 \bullet]$ and can rarely be achieved during a single session. The effectiveness of patient education has been demonstrated in a number of trials when it is provided as part of a multimodal management package. The provision of an online repository of information and resources which empower patients may be of particular benefit in supporting education, self-management, and improving symptom control and quality of life $[11 \bullet \bullet, 16 \bullet]$.

\section{Exercise}

Exercise has been identified as effective in managing a range of FM symptoms, including pain, reduced activity, and poor quality of life. A Cochrane review collated the evidence for 47 different types of exercise therapies and determined aerobic exercise to be associated with reductions

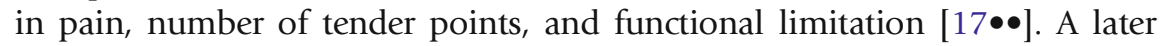
review found similar benefits in response to strengthening exercises [18], and more recent research has supported the effectiveness of aquatic exercise [19]. Given a lack of evidence to support any one specific exercise modality over others, cost, patient preference, and the likelihood of long-term adherence are factors to discuss and agree upon during the development of a management plan. Research that has objectively measured physical activity levels has determined that individuals with chronic pain are less active than those without chronic pain [20]. This relationship may, in part, be explained by beliefs held by individuals with chronic pain regarding movement and symptom exacerbation [21]. Unhelpful beliefs may be given traction if exercise is not introduced in a graded manner, with negative experiences after unpaced exercise deterring future participation. Indeed, the word "exercise" itself may cause trepidation in some individuals with chronic pain, so focusing on increasing activity in general may be a preferable starting point. Guidelines have proposed sessions of moderate to mild intensity activity for a 30-min duration at least two times a week $[11 \bullet \bullet, 12 \bullet, 13 \bullet]$. Garcia et al. found exercise to be included in all CPGs identified up to 2014 and awarded it the highest ratings for both level of

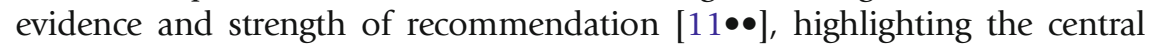
role it plays in FM symptom management.

Cognitive behavioral therapy (CBT) can be used to target negative thoughts about pain and its exacerbation on activity and can support behavior change through improvements in symptom management self-efficacy $[12 \bullet, 13 \bullet]$. 
Along with exercise, CBT received the highest rating for level of evidence in a synthesis of CPGs [11••]. A 2013 meta-analysis of 23 randomized controlled trials investigated the impact of CBT on pain, function, and mood in individ-

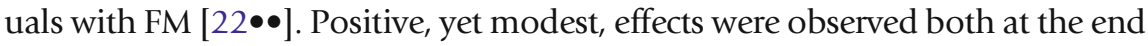
of treatment and in the longer term for all outcomes. Evidence suggests that CBT is effective regardless of mode of delivery (one-to-one, group therapy, or internet-based). The choice of medium may be informed by availability, cost-effectiveness, location and, importantly, the patient's preference and existing commitments (for example, occupational or homecare duties and geographical location) [23]. Consideration of, and response to, these factors may support adherence to a full course of therapy, with consequent associated benefits. An important point to note is that acceptance of CBT may be reduced if it is perceived as a purely psychological intervention [15•]. Instead, CBT as one facet of a multimodal management plan should be fully explained as part of the educational component. It is also too simplistic to consider CBT as a single therapeutic entity which may be "taken off the shelf" and applied uniformly. Existing programs are not necessarily underpinned by the same behavioral models, and perhaps the most optimal strategy is to enable patients to inform the selection of specific themed CBT modules which align best with their individual needs. As an example, some patients may well benefit more from targeting of their fatigue rather than their pain. Such program versatility has been successfully tested and resulted in significant benefits out to 2 years [24]. Finally, CBT programs may be delivered at varying intensities. So called "low grade" CBT has been successfully delivered in many disorders by trained health professionals who do not have a background in psychology [25]. Such an approach is clearly attractive in many health care systems where access to psychologists is limited by costs and/or limited availability.

\section{Pharmacologic treatment}

The pharmacological treatment of FM is largely an "off-label", testament to the fact that, in the USA, only three drugs are currently Food and Drug Administration (FDA)-approved (pregabalin, duloxetine, and milnacipran). In comparison, two are approved by Health Canada (pregabalin and duloxetine) and none are approved by the European Medicines Agency [26•]. The efficacy of a broad range of pharmacological treatments has been investigated in randomized controlled trials. In general, pharmacological treatment, restricted to the shortest duration possible, should be reserved for cases of severe and uncontrolled symptoms, including pain, sleep, and mood disorders, when nonpharmacological options have been exhausted.

\section{Anti-depressants}

Classes of anti-depressant frequently used to treat individuals with FM symptoms include tricyclic anti-depressants, Serotonin Norepinephrine Reuptake Inhibitors (SNRIs), and Selective Serotonin Reuptake Inhibitors (SSRIs). Pain reductions resulting from their use are attributed to modulating effects on serotonin and norepinephrine in descending inhibitory pain pathways [27]. 
Amitriptyline is the most studied anti-depressant in the treatment of FMrelated symptoms. Clinical trials have demonstrated reductions in pain, sleep problems, and fatigue, although the methodological quality of studies has been questioned [28]. Improvements have been identified 6 to 8 weeks after commencement at low doses ( $25 \mathrm{mg} /$ day), but no benefit identified with either an increased dose $(50 \mathrm{mg} /$ day $)$ or after a longer duration (12 weeks) when compared to placebo [29]. The Garcia et al. summary of published CPGs rated the level of evidence for amitriptyline as A1, recommending its prescription, at a dose of $10-50 \mathrm{mg} /$ day, for those with severe, uncontrolled pain and sleep problems $[11 \bullet \bullet, 12 \bullet, 30 \bullet]$. Common side effects include drowsiness, dry mouth, and weight gain, and many patients find that such problems outweigh any gains in symptom relief.

Serotonin norepinephrine reuptake inhibitors

Duloxetine A systematic review of the efficacy of duloxetine reported a reduction of greater than $30 \%$ for pain effective doses being between $60-120 \mathrm{mg} /$ day, with no difference detected between doses [31 $\bullet$ and lower doses (20-30 mg/day) not demonstrating significant effects. Modest, positive effects on sleep and function have also been reported [32•]. The Spanish and German guidelines, published in 2011 and 2012, respectively $[12 \bullet, 30 \bullet]$, identified duloxetine as the preferred SNRI, prescribed at a dose of $60 \mathrm{mg} /$ day, for those with comorbid anxiety or depression in cases where amitriptyline is contraindicated or ineffective (level of evidence A1) $[11 \bullet \bullet]$. Possible side effects of duloxetine include nausea, palpitations, headache, fatigue, tachycardia, and hypertension [15•].

Milnacipran A Cochrane review conducted by Hauser et al. that investigated the effects of SNRIs on FM symptoms identified five studies that compared milnacipran with placebo [32•]. Its use was associated with a small incremental benefit for pain reduction and slight improvements in fatigue and quality of life but no improvements detected for sleep problems. An effective dose of 100-200 mg/day has been proposed with potential side effects including nausea, palpitations, headache, fatigue, tachycardia, and hypertension [15•]. It has been suggested that, as milnacipran is slightly more noradrenergic than duloxetine, it may be more suitable for individuals presenting with fatigue and memory problems $[15 \bullet]$. However, as it may also be more likely to precipitate hypertension, careful balancing of benefits and risks on a case-by-case basis is required.

Selective serotonin reuptake inhibitors

SSRIs used to treat FM symptoms include fluoxetine, paroxetine, and sertraline. In a meta-analysis of the effects of fluoxetine, a moderate effect on pain and modest effects on sleep and fatigue were detected [33]. Side effects of SSRIs include nausea, sexual dysfunction, and weight gain [15•]. Fluoxetine or paroxetine (20-40 mg/day) have been identified by two 2012 guidelines as worthy of consideration for those with comorbid anxiety of depression $[12 \bullet 13 \bullet]$. 


\section{Anticonvulsants}

The analgesic effect of anticonvulsants is thought to occur through a reduction in the release of neurotransmitters involved in pain processing, e.g., glutamate and substance P [34]. This class of drugs was developed, and subsequently licensed, as antiepileptics but they are now commonly used in the management of chronic pain [26•].

Pregabalin Pregabalin is FDA-approved for FM symptom management. A Cochrane review from 2013 reported a $30 \%$ reduction in pain but a modest effect on fatigue and sleep and no impact on function [35•]. Standard dosages range from 50 $450 \mathrm{mg} /$ day $[11 \bullet \bullet, 12 \bullet, 30 \bullet]$, to up to $600 \mathrm{mg} /$ day, in divided doses. Side effects include sedation, weight gain, and dizziness [15•]. Garcia et al. recommend its consideration if amitriptyline is contraindicated or ineffective (level of evidence: A2 - several randomized clinical trials have provided evidence $p<0.01$ without

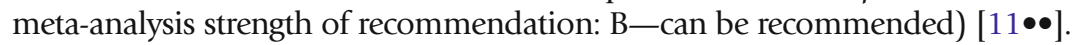

Gabapentin The use of gabapentin for FM symptom management is relatively understudied. A Cochrane review that investigated gabapentin in the treatment of neuropathic pain and FM (date of most recent search January 2011) [36•] included only one study that investigated its effect on FM symptoms [37]. This study reported an improvement in pain (significant $30 \%$ reduction) and function and a modest effect on sleep problems. A dose range of $800-2400 \mathrm{mg} /$ day, in divided doses, has been suggested. Side effects include sedation, weight gain, and dizziness [15•].

\section{Nonsteroidal anti-inflammatory drugs (NSAIDs)}

There is no evidence to support the efficacy of NSAIDs in managing FM-related pain, with trials consistently demonstrating no benefit over placebo [38]. Indeed, there is evidence to suggest that drugs frequently used to treat peripheral pain, such as NSAIDs and opioids, are not only ineffective, but may exacerbate symptoms [15•]. Given the potentially deleterious side effects affecting the gastrointestinal, renal, and cardiac systems, this class of drugs should only be prescribed in cases of persistent and moderate to severe peripheral pain. In such instances, the lowest effective dose possible should be prescribed for the shortest duration to minimize any secondary effects [15•].

\section{Opiods}

The apparent hyperactivity of the endogenous opioid system in FM perhaps explains the general inefficacy of opiods [15•]. Tramadol has however been commonly used, although any benefit may actually relate to its mild SNRI effects. Recommendations regarding tramadol use are inconsistent across CPGs. Its use has been associated with significant pain reduction (30 \%) [39], although Garcia et al. recommend its use only once all other pharmacological options have been exhausted and in cases of persistent moderate or severe pain [11••]. Tramadol dosage, with or without acetaminophen, has been suggested at 50-100 mg every $6 \mathrm{~h}$. Side effects to be cognizant of include sedation, possible addiction, the development of tolerance, and opioid-induced hyperalgesia [15•].

\section{Complementary and alternative therapies}

In their systematic review of CPGs for the management of FM, Garcia et al. identified four alternative therapies that were recommended by more than one 


\section{Conclusions}

guideline: acupuncture, Qi Gong, Tai Chi, and yoga [11••]. However, given limited corroboration of findings, further research is required to support the effectiveness of these therapeutic options, as well as to determine the benefit of other alternative or complementary approaches. However, as adjuncts to nonpharmacological and pharmacological interventions, patient preference and selection of complementary or alternative therapies may provide a useful way of engaging individuals with active symptom management, encouraging "buy-in" to self-care, and potentially enhancing self-efficacy [15•]. Furthermore, in circumstances where all else fails, patient-directed alternative approaches (as long as they are safe) may most optimally tap into clinically important placebo responses.

A range of treatment modalities to address complex and heterogeneous FM symptoms should be explored in collaboration with patients. Understanding the individual's needs and specific symptoms that are restricting activities and participation is key to the development of tailored treatment plans. Education, exercise, and active self-management are highly recommended, providing the core around which pharmacological and nonpharmacological treatments and complementary and alternative therapy adjuncts can be supplemented. Importantly, education should acknowledge the limits of pharmacological treatments in resolving symptoms, and selfmanagement should be promoted within the context of realistic expectation setting. Exercise comes most highly recommended followed by CBT. Short courses of pharmacological treatment are indicated when symptoms are particularly burdensome. Overall, a personalized approach is indicated, where, above the staple of education and encouragement of positive exercise, sleep and stress reduction behaviors, and additional psychological interventions (i.e., CBT) may be of benefit for those with unhelpful coping strategies and pharmacotherapy may be indicated in cases of severe pain, sleep disturbance, or mood disorders. Through actively involving patients in the design of a multimodal management plan that takes into consideration the preferred method and timing of delivery, self-efficacy and a sustained commitment to behavior change may provide the optimal atmosphere for long-term symptom management.

\section{Compliance with Ethical Standards}

\section{Conflict of Interest}

Daniel Whibley declares that he has no conflict of interest.

Linda E Dean declares that he has no conflict of interest.

Neil Basu declares that he has no conflict of interest.

\section{Human and Animal Rights and Informed Consent}

This article does not contain any studies with human or animal subjects performed by any of the authors. 
Open Access This article is distributed under the terms of the Creative Commons Attribution 4.0 International License (http://creativecommons.org/licenses/by/4.0/), which permits unrestricted use, distribution, and reproduction in any medium, provided you give appropriate credit to the original author(s) and the source, provide a link to the Creative Commons license, and indicate if changes were made.

\section{References and Recommended Reading}

Papers of particular interest, published recently, have been

highlighted as:

- Of importance

-• Of major importance

1. Inanici F, Yunus MB. History of fibromyalgia: past to present. Curr Pain Headache Rep. 2004;8:369-78.

2. Gowers WR. A lecture on lumbago: its lessons and analogues. BMJ. 1904;i:117-21.

3. Hench PK. Nonarticular rheumatism, 22nd rheumatism review: review of the American and English literature for the years 1973 and 1974. Arthritis Rheum. 1976;19(suppl):1081-9.

4.• Wolfe F, Smythe HA, Yunus MB, et al. The American College of Rheumatology 1990 Criteria for the Classification of Fibromyalgia: report of the Multicenter Criteria Committee. Arthritis Rheum. 1990;33:160-72.

The original Amercian College of Rheumatology classification criteria for fibromyalgia.

5.• Wolfe F, Clauw DJ, Fitzcharles MA, et al. The American College of Rheumatology preliminary criteria for fibromyalgia and measurement of symptom severity. Arthritis Care Res. 2010;62(5):600-10.

Revised American College of Rheumatology criteria for fibromyalgia, shifting the emphasis from classification to diagnosis.

6.• Wolfe F, Clauw D, Fitzcharles M, et al. Fibromyalgia criteria and severity scales for clinical and epidemiological studies: a modification of the ACR Preliminary Diagnostic Criteria for Fibromyalgia. J Rheumatol. 2011;38(6):1113-22.

American College of Rheumatology criteria for fibromyalgia suitable for use in epidemiological and clinical research.

7. Queiroz LP. Worldwide epidemiology of fibromyalgia Curr Pain Headache Rep. 2013;17(8):1-6.

8. Wolfe F, Ross K, Anderson J, et al. The prevalence and characteristics of fibromyalgia in the general population. Arthritis Rheum. 1995;38:19-28.

9. Vincent A, Lahr B, Wolfe F, et al. Prevalence of fibromyalgia: a population-based study in Olmsted county, Minnesota, utilizing the Rochester epidemiology project. Arthritis Care Res. 2013;65:786-92.

10. Carville SF, Arendt-Nielsen S, Bliddal H, Blotman F, Branco JC, Buskila D, et al. EULAR evidence-based recommendations for the management of fibromyalgia syndrome. Ann Rheum Dis. 2008;67:536-41.

Informed by systematic review and expert consensus, these European League Against Rheumatism guidelines are currently in the process of being updated.

11.• Ángel García D, Martínez Nicolás I, Saturno Hernández PJ. Abordaje clínico de la fibromialgia: síntesis de recomendaciones basadas en la evidencia, una revisión sistemática. Reumatol Clin. 2016;12(2):65-71.

A narrative synthesis of clinical practice guidelines published up to 2014.

12. Eich W, Häuser W, Arnold B, Jäckel W, Offenbächer M, Petzke F, et al. Fibromyalgia syndrome. Definition, classification, clinical diagnosis and prognosis. Schmerz. 2012;26:247-58.

The German clinical practice guideline for fibromyalgia.

13. Fitzcharles M-A, Ste-Marie PA, Goldenberg DL, Pereira JX, Abbey S, Choinière M, et al. 2012 Canadian guidelines for the diagnosis and management of fibromyalgia syndrome: executive summary. Pain Res Manag. 2012;18:119-26.

The Canadian clinical practice guideline for fibromyalgia.

14. Bennett RM, Friend R, Jones KD, Ward R, Han BK, Ross RL. The Revised Fibromyalgia Impact Questionnaire (FIQR): validation and psychometric properties. Arthritis Res Ther. 2009;11:R120.

15. Clauw DJ. Fibromyalgia. A Clinical Review. JAMA. 2014;311(15):1547-55.

A comprehensive review of the epidemiology, pathophysiology and clinical management of fibromyalgia.

16. University of Texas, School of Nursing FNPP, NGC. Management of fibromyalgia syndrome in adults. Rockville, MD: Agency for Healthcare Research and Quality (AHRQ); 2009.

A clinical practice guideline developed in the United States.

17.• Busch AJ, Barber KA, Overend TJ, Peloso PMJ, Schachter CL. Exercise for treating fibromyalgia syndrome. Cochrane Database Syst Rev. 2007;2007(4), CD003786. A systematic review of randomized trials of the effectiveness of exercise to treat fibromyalgia symptoms.

18. Busch AJ, Webber SC, Richards RS, Bidonde J, Schachter CL, Schafer LA, et al. Resistance exercise training for fibromyalgia. Cochrane Database Syst Rev. 2013;2013(12):CD010884.

19. Bidonde J, Busch AJ, Webber SC, Schachter CL, Danyliw A, Overend TJ, et al. Aquatic exercise training for fibromyalgia. Cochrane Database Syst Rev. 2014;2014(10):CD011336.

20. Dansie EJ, Turk DC, Martin KR, Van Domelen DR, Patel KV. Association of Chronic Widespread Pain with 
Objectively Measured Physical Activity in Adults: Findings from the National Health and Nutrition Examination Survey. J Pain. 2014;15(5):507-15.

21. Gatchel RJ, Neblett R, Kishino N, Ray CT. FearAvoidance Beliefs and Chronic Pain. J Orthop Sports Phys Ther. 2016;46(2):38-43.

22.• Bernardy K, Klose P, Busch AJ, Choy EHS, Häuser W. Cognitive behavioural therapies for fibromyalgia. Cochrane Database Syst. Rev. 2013;(9):CD009796. A systematic review of randomized trials of the outcome of cognitive behavioral therapies in treating fibromyalgia symptoms.

23. Williams R, Farquharson L, Palmer L, Bassett P, Clarke J, Clark DM, et al. Patient preference in psychological treatment and associations with self-reported outcome: national cross-sectional survey in England and Wales. BMC psychiatry. 2016;16(4):1-8.

24. Beasley M, Prescott GJ, Scotland G, McBeth J, Lovell K, Keeley $\mathrm{P}$, et al. Patient-reported improvements in health are maintained 2 years after completing a short course of cognitive behaviour therapy, exercise or both treatments for chronic widespread pain: long-term results from the MUSICIAN randomised controlled trial. RMD open. 2015;1(1):e000026.

25. Brunner E, De Herdt A, Minguet P, Baldew SS, Probst $\mathrm{M}$. Can cognitive behavioural therapy based strategies be integrated into physiotherapy for the prevention of chronic low back pain? A systematic review. Disabil Rehabil. 2013;35(1):1-10.

26. Calandre EP. Rico-Villademoros, Slim M. An update on pharmacotherapy for the treatment of fibromyalgia. Expert Opin Pharmacother. 2015;16(9):1347-68.

A review of the evidence for pharmacological treatments for fibromyalgia.

27. Dharmshaktu P, Tayal V, Kalra BS. Efficacy of antidepressants as analgesics: a review. J Clin Pharmacol. 2012;52(1):6-17.

28. Häuser W, Petzke F, Üçeyler N, Sommer C. Comparative efficacy and acceptability of amitriptyline, duloxetine and milnacipran in fibromyalgia syndrome: a systematic review with meta-analysis. Rheumatology. 2011;50(3):532-43.

29. Nishishinya B, Urrutia G, Walitt B, Rodriguez A, Bonfill $\mathrm{X}$, Alegre $\mathrm{C}$, et al. Amitriptyline in the treatment of fibromyalgia: a systematic review of its efficacy. Rheumatology. 2008;47(12):1741-6.

30. Agència d'Informació, Avaluació i Qualitat en Salut. Fibromiàlgia i síndrome de fatiga crònica: recomanacions sobre el diagnòstic i tractament.
Barcelona: Agència d'Informació, Avaluació i Qualitat en Salut. Servei Català de la Salut. Departament de Salut. Generalitat de Catalunya; 2011.

The Spanish clinical practice guideline for fibromyalgia.

31. Lunn MP, Hughes RA, Wiffen PJ. Duloxetine for treating painful neuropathy, chronic pain or fibromyalgia. Cochrane Database Syst Rev. 2014;1, CD007115.

This systematic review includes the findings from three randomized trials that investigated the effectiveness of duloxetine in treating fibromyalgia.

32.• Häuser W, Urrútia G, Tort S, Üçeyler N, Walitt B. Serotonin and noradrenaline reuptake inhibitors (SNRIs) for fibromyalgia syndrome. Cochrane Database Syst Rev. 2013; (1):CD010292.

This systematic review includes the findings from 10 randomized controlled trials. Five compared duloxetine to placebo;

five compared milnacipran to placebo.

33. Perrot S, Russell IJ. More ubiquitous effects from nonpharmacologic than from pharmacologic treatments for fibromyalgia syndrome: A meta-analysis examining six core symptoms. Eur J Pain. 2014;18(8):1067-80.

34. Menzies V. CE: Fibromyalgia Syndrome: Current Considerations in Symptom Management. Am J Nurs. 2016;116(1):24-32.

35.• Üçeyler N, Sommer C, Walitt B, Häuser W. Anticonvulsants for fibromyalgia. Cochrane Database Syst Rev. 2013;(10):CD010782.

This systematic review includes the findings from eight randomized controlled trials. Anticonvulsants assessed were pregabalin, gabapentin, lacosamide and levetiracetam.

36. Moore RA, Wiffen PJ, Derry S, McQuay HJ. Gabapentin for chronic neuropathic pain and fibromyalgia in adults. Cochrane Database Syst Rev. 2011;(3):CD007938.

This systematic review includes the findings from 29 randomized trials that investigated the effectiveness of gabapentin at a daily dose of at least $1200 \mathrm{mg}$.

37. Arnold LM, Goldenberg DL, Stanford SB, Lalonde JK, Sandhu HS, Keck Jr PE, et al. Gabapentin in the treatment of fibromyalgia: a randomized, double-blind, placebo-controlled, multicenter trial. Arthritis Rheum. 2007;56(4):1336-44.

38. Lautenschläger J. Present state of medication therapy in fibromyalgia syndrome. Scand J Rheumatol. 2000;29:32-6.

39. Roskell NS, Beard SM, Zhao Y, Le TK. A meta-analysis of pain response in the treatment of fibromyalgia. Pain Pract. 2011;11(6):516-27. 